\title{
Designing and Evaluation of Bagasse Powered Preheating Device for Seed Cane Hot- water Treatment Plant
}

\author{
Bandara W.B.M.A.C. ${ }^{{ }^{*}}$, Ariyawansha K.T. ${ }^{2}$ and Rupasinghe C.P. ${ }^{1}$ \\ ${ }^{I}$ Faculty of Agriculture, University of Ruhuna, Sri Lanka \\ ${ }^{2}$ Division of Mechanization Technology, Sugarcane Research Institute, Sri Lanka \\ *chathu.anushk@gmail.com
}

\begin{abstract}
As a solution for the energy crisis facing today, the biomass from the sugarcane industry plays major role as an energy source in developing countries. Sugarcane (Saccarhum officinarum) is a globally important source of commercial sugar, which accounts for over 75 percent of the world sugar production. It is estimated that, 30 percent of wet bagasse is produced in a normal sugar mill. Sugarcane bagasse has a heating value of $16792.44 \mathrm{~kJ} / \mathrm{kg}$. There is a high potential for using bagasse as a biomass energy source of agricultural sector when considering its thermal properties and the availability.

Due to non-availability of disease-free healthy planting materials, sugarcane productivity in Sri Lanka has decreased. Hot water treatment of sugarcane planting material is practiced to control systemic diseases of sugarcane such as ratoon stunting disease and smut. Operating of the existing hot water treatment plants require high electricity for the initial heating process which is very costly and time consuming. This research is focused on designing and evaluating of a bagasse powered pre-heating device for seed cane hot water treatment plant for saving energy and time.

The flue gas generated by burning of bagasse was used as the energy source for steam generation inside the pre-heating device. The pre-heating device was designed by combining the concepts of water tube boiler and shell boiler so that the device is named as the combined steam generator. Specifications of the preheating device were calculated according to the heat energy requirement of feed water, steam and fuel energy. Conceptual design for the new preheating device was developed considering the system requirements. Based on the concept, a detail design of each part of the device was developed with properly defined dimensions, using a parametric 3D modeling software and simulation process carried out using finite element analysis (FEA). Then the preheating device was completely assembled with fabricated parts. According to the evaluation results, efficiency of the combined steam generator was $80.14 \%$. So the time and the electric energy consumption are reduced by $37 \%$ and $99.17 \%$ respectively.
\end{abstract}

Keywords: Seed cane, Bagasse, Hot water treatment, Biomass energy, Steam

Proceedings of the International Forestry and Environment Symposium 2016, Department of Forestry and Environmental Science, University of Sri Jayewardenepura, Sri Lanka. 